\title{
A Puzzling Case of Biliary Stricture with Calcified Liver Nodules
}

Leow VMa , Faizah $\mathrm{MS}^{\mathrm{b}}$, Yang $\mathrm{KF}^{\mathrm{c}}$, Hasnan $\mathrm{MN}^{\mathrm{c}}$, Manisekar SSc

${ }^{a}$ Oncology Cluster, Advanced Medical and Dental Institute (AMDI), Universiti Sains Malaysia, Penang, Malaysia ${ }^{b}$ Department of Surgery, Sultanah Bahiyah Hospital, Alor Setar, Kedah, Malaysia

'Hepatobiliary Unit, Department of Surgery, Sultanah Bahiyah Hospital, Alor Setar, Kedah, Malaysia

\section{ABSTRACT}

Tuberculous (TB) biliary stricture with calcified liver nodules rendering obstructive jaundice is a rare clinical phenomenon. Recently, we encountered a young patient with obstructive jaundice who was investigated in a general hospital. He was sent to our hospital for subsequent management after undergoing a series of investigations and biliary stenting. The radiological imagings performed revealed multiple calcified lesions in the liver with proximal bile duct strictures. Blood investigations, tumor markers and tuberculous work up were not remarkable. Subsequently, he underwent laparotomy and biliary reconstruction. Postoperatively, he was discharged well. Histopathological examination of the hepatoduodenal nodes showed chronic infections and granulomatous lymphadenitis, suspicious of a mycobacterium infection.

KEYWORDS: Biliary Tuberculosis, biliary stricture, calcification, liver nodules, cholangiocarcinoma

\section{INTRODUCTION}

Hepatobiliary tuberculosis is uncommon and it can mimic liver tumors causing biliary obstruction, cholangiocarcinoma, and periampullary tumors. The clinical presentations can be misleading. This explained the different modes of diagnostic and

antegrade biliary stenting to surgical biliary reconstruction. Because of that the diagnosis is often established at operation, after the surgery via histology or by PCR assay. Invariably, the treatment mandates anti-tubercular therapy. treatment regimens ranging from endoscopic or

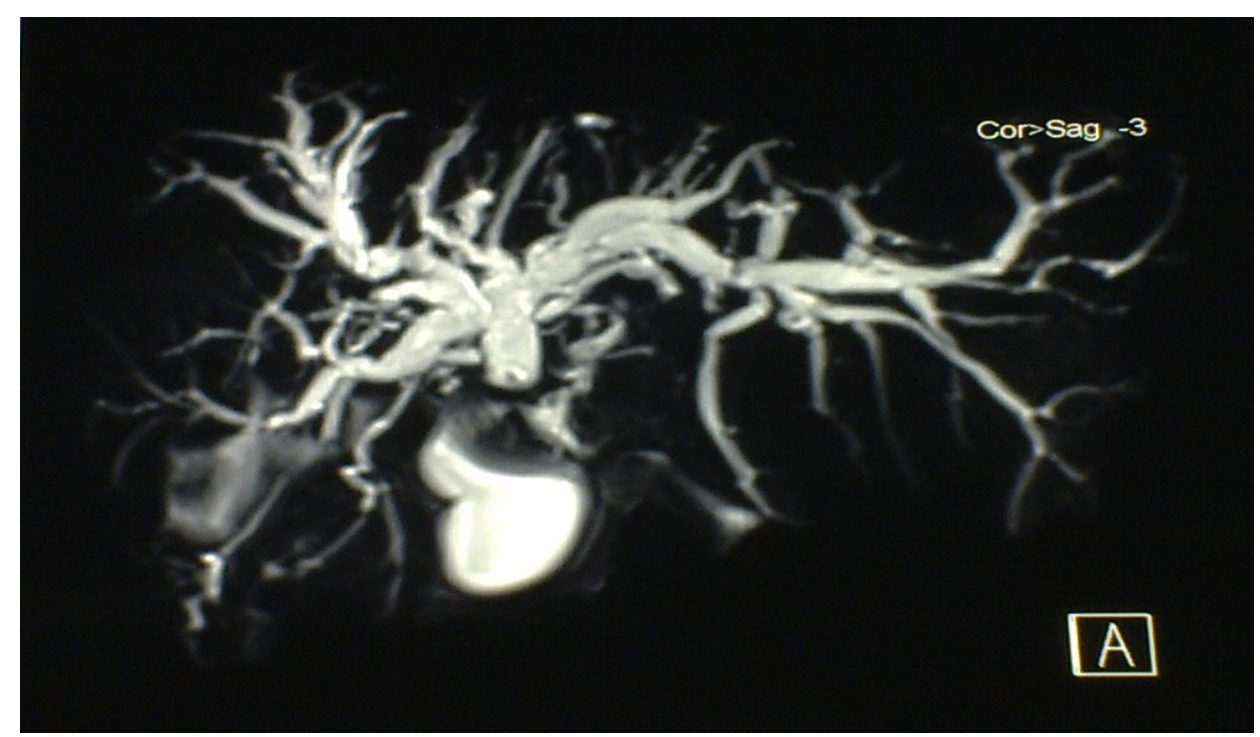

Figure 1. MRCP revealed stricture at common hepatic duct

\section{Corresponding author:}

Dr Leow Voon Meng

General Surgeon/ Lecturer of Surgery

Advanced Medical and Dental Institute (AMDI)

Universiti Sains Malaysia, Bandar Putra Bertam

13200, Kepala Batas, Penang, Malaysia.

Tel: 604-5622005, 604-5622046

Fax: 604-5622461, 604-5622462

Email: leowvm@amdi.usm.edu.my

\section{CASE REPORT}

A 26-year-old gentleman who works as a teacher was referred from Queen Elizabeth Hospital, Sabah (West Malaysia), to Sultanah Bahiyah Hospital, Kedah, Hepatopancreatic Biliary Center, northern state of Peninsular Malaysia on February 2011 for management of obstructive jaundice. The patient presented with a two-month history of right hypochondriac and epigastric pain associated with fever. Later, he had jaundice, tea-colored urine and pale colored stool. 
His physical findings were not significant except or the jaundice. Work-ups for tuberculosis were all negative. Liver function test revealed the obstructive picture. The Ca 19-9 and CEA were within normal limits. His upper and lower gastrointestinal scopes were unremarkable. Endoscopic retrograde cholangiopancreaticography (ERCP) was carried out, which demonstrated stricture formation at the hepatic duct confluence. Magnetic resonance cholangiopancreaticography (MRCP) showed a stricture at the proximal common bile duct (figure 1). A three-phase computed to- mography (CT) of the liver was also done displayed hepatolithiasis withmultiple calcified periportal lymphadenopathy (figure 2). The blood investigations taken at our centre did not show any significant abnormality except for elevated $C$ - reactive protein (CRP). His hemoglobin level was $15.4 \mathrm{~g} / \mathrm{dL}$, white cell count was 11000 , renal profile was normal, albumin was $44 \mathrm{mmol} / \mathrm{L}$, total bilirubin was $18 \mathrm{umol} / \mathrm{L}$, ALP was $276 \mathrm{u} / \mathrm{L}$, gamma GT was $246 \mathrm{u} / \mathrm{L}$, ALT was $91 \mathrm{u} / \mathrm{L}$, ESR was $1.0 \mathrm{~mm} / \mathrm{hr}$ and CRP was $68 \mathrm{mg} / \mathrm{L}$.

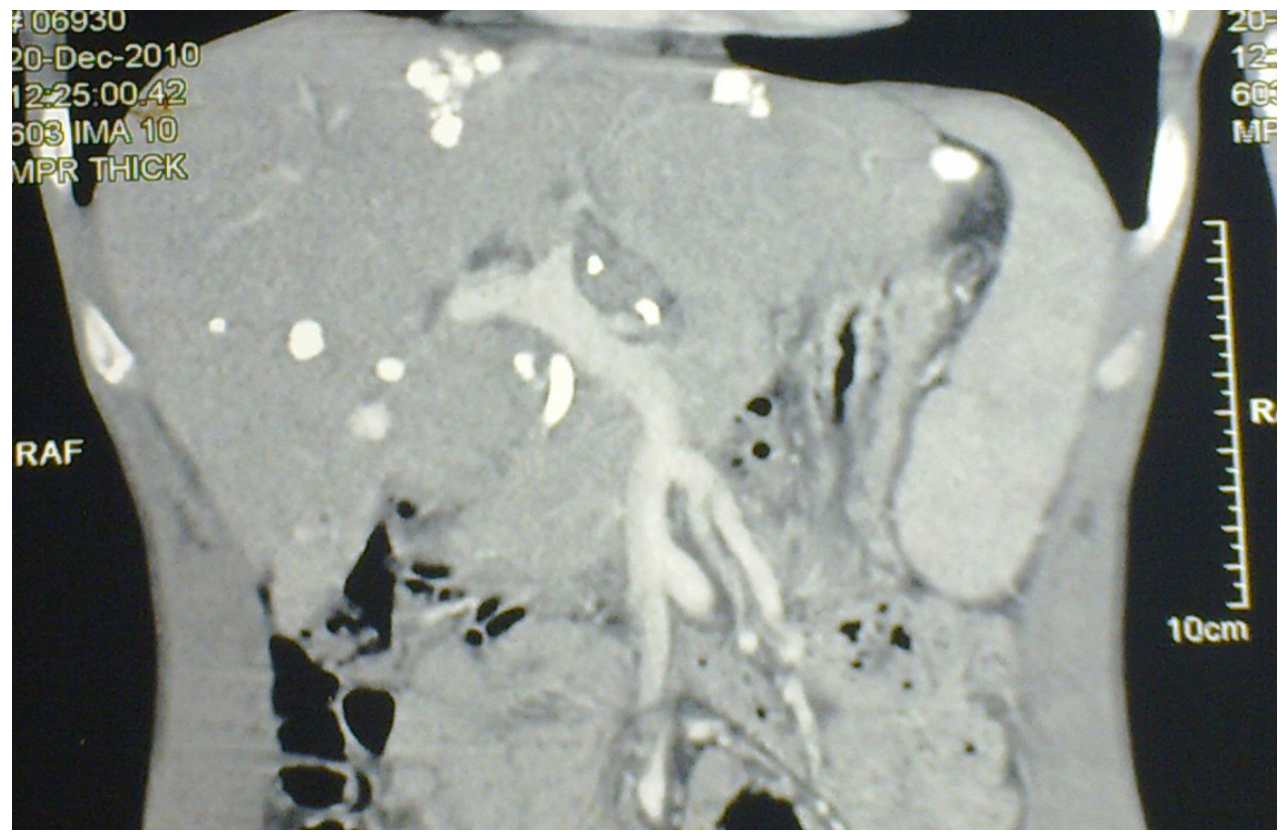

Figure 2. Coronal view of CT liver displayed hepatic calcifications situated at the liver surface

Subsequently, heunderwentalaparotomy, intraoperative choledochoscopy, choledochectomy and Roux-en Y hepaticojejunostomy. The operative findings were dilated intrahepatic ducts bilaterally with common hepatic duct srticture, hepatoduodenal lymphadenopathy and multiple hard whitish-yellow liver nodules (figure 3). They were not typical of secondaries and could be of inflammatory in origin. Liver was not cirrhotic, and no biliary stone was seen. Post operatively, the patient recovered well. Bile for AFB was negative. He was discharged back to his hometown in Sabah as requested by the patient. His histopathological examination report of the hepatoduodenal lymph nodes revealed granulomatous lymphadenitis with suspicious of a mycobacterium infection. Livernodules were calcified. Both the gallbladder and common bile duct were consistent with chronic cholecystitis and chronic cholangitis respectively. He was started on anti-tubercular treatment. The patient was followed up and was doing well.

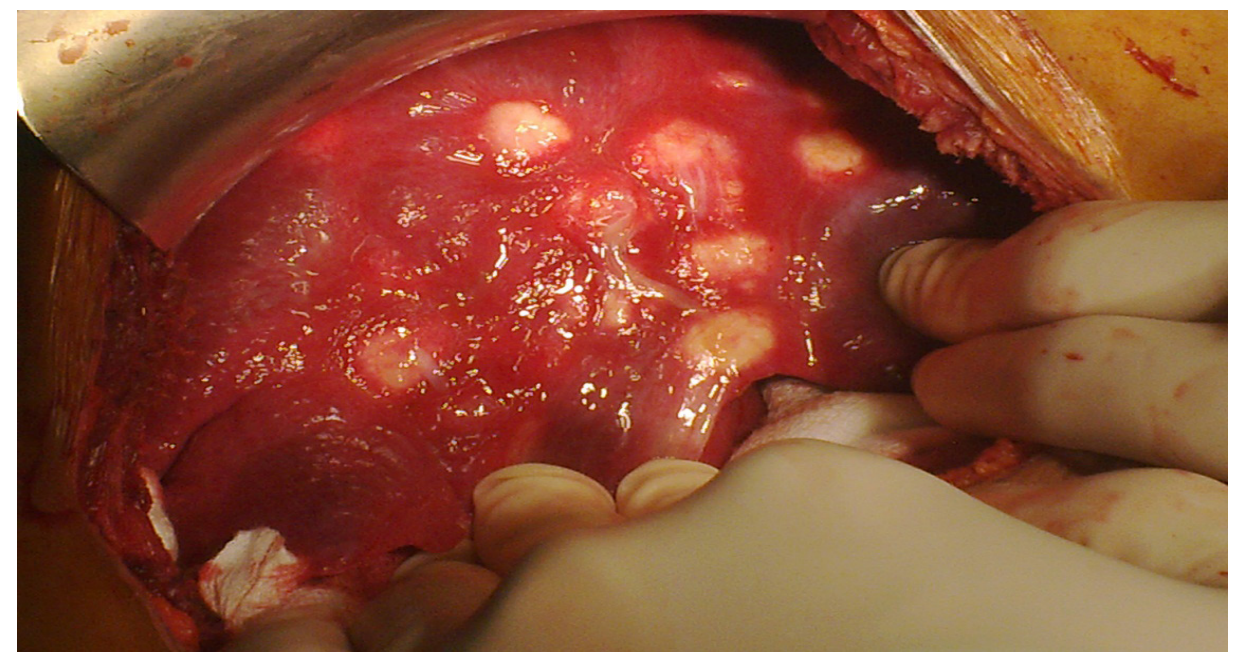

Figure 3. Intraoperative photograph of multiple calcified liver nodules seen on CT images 
Abdomen is one of the common extrapulmonary manifestations of disseminated tuberculous infection. ${ }^{1}$ Mycobacterium tuberculosis infects the biliary system via hematogenous route from the lungs or lymphatics from another intra-abdominal source of infection. The common bile duct involvement is thought to be the result of the spread of caseous material from the portal tract or secondary inflammation related to periportal adenitis. ${ }^{2}$ Tubercular biliary strictures can be classified as type 1, 2, 3 and further sub-classified into intrinsic or extrinsic according to the location and nature of the obstruction (table 1). Left untreated, biliary tuberculosis can lead to cholestasis, recurrent cholangitis (overt or subclinical), secondary biliary cirrhosis and secondary hepatolithiasis. ${ }^{2}$

Table 1. Types of Tubercular Biliary Strictures

\begin{tabular}{|l|l|l|}
\hline & Intrinsic (Intramural) & Extrinsic (Nodal) \\
\hline Type 1, Extrahepatic & Common bile duct stricture & $\begin{array}{l}\text { Compression by enlarged } \\
\text { pericholedochal lymph nodes }\end{array}$ \\
\hline Type 2, Intrahepatic & Intrahepatic strictures & $\begin{array}{l}\text { Compression by enlarged perihilar } \\
\text { lymph nodes }\end{array}$ \\
\hline Type 3, Combined & $\begin{array}{l}\text { Extrahepatic and intrahepatic } \\
\text { strictures }\end{array}$ & $\begin{array}{l}\text { Combination of biliary strictures } \\
\text { and lymph node compression }\end{array}$ \\
\hline
\end{tabular}

Source: Sriram PV, Rao GV, Reddy DN. Endoscopic management of benign biliary obstruction. Available at www. bhj.org/ journal/2002_4404_oct/ therap_543.htm. Accessed 4 Jan 2007.

The most common cause of hepatic calcification is due to granuloma formation as a result of inflammatory condition. Most of the patients who have these lesions are clinically asymptomatic. This represents previous infection in the liver either from tuberculosis or histoplasmosis. Calcified granulomas are usually small lesions and less than $2 \mathrm{~cm}$ in diameter. They may be solitary or multiple as seen in our patient. The calcification typically involves the entire lesion which appears as a dense mass that can produce artifacts in the CT image. ${ }^{3}$

Cytology or tissue diagnosis is crucial for the diagnosis of biliary tuberculosis. The specimens can be obtained by endoscopic brush cytology/ biopsy ${ }^{4}$ or by fine needle biopsy of involved lymph nodes using ultrasound or CT guided percutaneous procedure. ${ }^{5}$ Polymerase chain reaction (PCR) assay is another alternative method of demonstrating mycobacterial DNA. ${ }^{6}$ Other diagnostic tool, include obtaining tissue specimens by laparoscopic technique or endoscopic ultrasound (EUS) FNA. ${ }^{7}$

The clinical dilemma that we faced was the possibility of malignancy in this patient. In addition, there was no clinical and biochemical evidence of tuberculous infection. Based on the literature review the diagnosis of tuberculous infection of the biliary system is encountered in a variety of settings. They are often established at operation; post operatively by histology or by PCR technique. ${ }^{8}$

The treatment of tuberculosis of the biliary tree is antitubercular therapy. This should combine with endoscopic sphincterotomy, dilatation and stenting if the biliary system is obstructed. ${ }^{9}$ The antitubercular regimen for extrapulmonary tuberculosis is recommended by the World Health Organization and the Joint Statement of American Thoracic Society, Centers for Disease Control and Prevention and the Infectious Diseases Society of America. ${ }^{10}$ Generally, the treatment regimen requires a duration of 6-9 months, with 2 months of isoniazid, rifampicin, pyrazinamide and ethambutol, followed by 4-7 months of isoniazid and rifampicin. ${ }^{10}$

We conclude that the clinical presentation of this disease entity can be challenging. A high index of suspicion and perseverance are essential in pursuing the diagnosis of biliary tuberculosis followed by antitubercular treatment.

\section{CONFLICT OF INTEREST}

None declared.

\section{REFERENCES}

1. Marshall JB. Tuberculosis of the gastrointestinal tract and peritoneum. Am J Gastroenterol 1993; 88:989-9.

2. Sriram PV, Rao GV, Reddy DN. Endoscopic management of benign biliary obstruction. [online] Available at www.bhj.org/ journal/2002_4404_ oct/ therap_543.htm. Accessed 4 Jan 2007.

3. Paley MR, Ros PR. Hepatic calcification. Radiol Clin North Am 1998; 36:391-8.

4. Bearer EA, Savides TJ, McCutchan JA. Endoscopic diagnosis and management of hepatobiliary 
tuberculosis. Am J Gastroenterol 1996; 91:2602-4.

5. Probst A, Schmidbaur W, Jechart G, et al. Obstructive jaundice in AIDS: diagnosis of biliary tuberculosis by ERCP. Gastrointest Endosc 2004; 60:145-8.

6. Anand BS, Schneider FE, El-Zaatari FA, et al. Diagnosis of intestinal tuberculosis by polymerase chain reaction on endoscopic biopsy specimens. Am J Gastroenterol 1994; 89:2248-9.

7. Woodfield JC, Windsor JA, Godfrey CC, et al. Diagnosis and management of isolated pancreatic tuberculosis: recent experience and literature review. ANZ J Surg 2004; 74:368-71.

8. Xia F, Poon RT, Wang SG, et al. Tuberculosis of pancreas and peripancreatic lymph nodes in immunocompetent patients: experience from China. World J Gastroenterol 2003; 9:1361-4.

9. Alvarez S. Hepatobiliary tuberculosis. J Gastroenterol Hepatol 1998; 13:833-9.

10. Blumberg HM, Burman WJ, Chaisson RE, et al. American Thoracic Society/ Centers for Disease Control and Prevention/ Infectious Diseases 